Case Report

\title{
Large Vaginal Varicosities in the Setting of Pregnancy without Known Hepatic or Vascular Risks: A Case Report and Review of the Literature
}

\author{
Mark Sueyoshi, ${ }^{1}$ Steven Clevenger ${ }^{(D},{ }^{2}$ and Elaine Hart ${ }^{3}$ \\ ${ }^{1}$ School of Medicine, University of California, Riverside, CA, USA \\ ${ }^{2}$ College of Osteopathic Medicine, Western University of Health Sciences, Pomona, CA, USA \\ ${ }^{3}$ School of Medicine, Loma Linda University, Loma Linda, CA, USA \\ Correspondence should be addressed to Steven Clevenger; sclevenger@westernu.edu
}

Received 1 September 2017; Accepted 9 December 2017; Published 22 January 2018

Academic Editor: Svein Rasmussen

Copyright (c) 2018 Mark Sueyoshi et al. This is an open access article distributed under the Creative Commons Attribution License, which permits unrestricted use, distribution, and reproduction in any medium, provided the original work is properly cited.

Pregnancy may cause the onset of vaginal or vulvar varicosities that may be a concern for hemorrhage risk during childbirth. A 38-year-old female G4P1112 at 34 weeks and 1 day was referred to an outpatient OB/Gyn clinic for evaluation of a large vaginal mass. The referring provider had concern for malignancy. Lesions of the vulva were biopsied and found to be benign. For two months prior to presentation, she was experiencing discomfort with walking, yellow vaginal discharge, and dysuria. Treatment with fluconazole showed no improvement. She denied any personal or family history of malignancies, varicosities, or hepatic issues. Past surgical history was significant for laparoscopic cholecystectomy and two cesarean sections. A large vaginal mass during pregnancy is a concern whether it is malignancy or large vaginal varicosities that may put the patient at risk of severe hemorrhage during childbirth. We concluded that the mass was large vaginal varicosities as there was no discernible etiology. A repeat cesarean section was recommended due to the risk of hemorrhage during childbirth. For long-term management, close observation postpartum was recommended. Spontaneous resolution is a potential outcome and this is what our patient experienced. Without an underlying etiology, supportive measures are the best options.

\section{Introduction}

Vaginal varicosities are part of a larger set of complications that can occur as a result of venous congestion and obstruction in pregnant and nonpregnant patients alike. This can lead to varicosities anywhere in the genital and pelvic region. The occurrence of genital varicosities in pregnancy is uncommon with vulvar varicosities occurring in $2-4 \%$ of pregnancies and vaginal varicosities being even less common $[1,2]$. One sample of 4676 patients seen in the St Mary's Hospital vein clinic showed that $4 \%$ of pregnant patients had perivulvar varicosities [3]. They usually develop after 12-26 weeks of pregnancy and largely self-resolve shortly after delivery [4-6]. Nonpregnancy-related causes of genital varicosities include portal hypertension and KlippelTrenaunay syndrome [7-10]. Vaginal varicosities can also be part of a larger syndrome called pelvic congestion syndrome which often presents in pregnant patients as a constellation of pelvic pain, dyspareunia, dysmenorrhea, dysuria, vulvar, and perivulvar varicosities $[1,11,12]$. Although generally small, vaginal and genital varicosities can become large enough that concern over rupture and subsequent hemorrhage during vaginal birth has been raised by some practitioners $[4,13]$. This has led some physicians to utilize cesarean section in selected cases to avoid the risk of hemorrhage, although due to limited reports the utility of this approach is not known $[13,14]$. In this case we present large vaginal varicosities in a 38-year-old G4P1112 at 34 weeks and 1 day of gestation varicosities for which hemorrhage was a concern.

\section{Case Presentation}

A 38-year-old female G4P1112 at 34-week and 1-day gestational age dated by last menstrual period presented to the outpatient clinic for her first obstetrical visit. She was referred for evaluation of a large vaginal mass by an outside 
provider over concern of potential malignancy. There were also vulvar lesions which were punch biopsied showing squamous vaginal mucosa with some reactive cellular changes. A transvaginal ultrasound detailed the presence of varicosities within the vaginal wall. The patient had no prior history of vaginal varicosities. Her obstetrics history was significant for 2 prior C-sections, 1 ectopic pregnancy, and diet-controlled gestational diabetes. The patient had been complaining for the past 2 months of yellow vaginal discharge, dysuria, and discomfort made worse with walking. She had been treated unsuccessfully with fluconazole for this pain in the past. Fetal anatomy survey at 26 weeks and 2 days demonstrated no maternal anomalies of the cervix. The fetus was found to have mild bilateral hydronephrosis at $4 \mathrm{~mm}$.

Our patient began menarche at age 12 and has been regular with a moderate flow lasting approximately 3 days. She has no known history of gynecologic diseases; STI screening with her last pap smear and HPV test were negative for abnormalities in October 2016. She has no history of past varicosities, coagulopathies, or hepatic disease. The patient had a significant past surgical history of laparoscopic cholecystectomy and hernia repair in 2014. She denied any personal or family history of cancer.

On physical exam, significant anterior and lateral vaginal wall clusters of soft varicosities were noted. The varicosities filled the vagina and protruded beyond the hymenal ring (Figures 1 and 2). A second opinion obtained by a GynOnc physician confirmed large vaginal varicosities by clinical exam. The patient was sent back to referring provider to continue prenatal care. The oupatient OB/Gyn consulting physician recommended repeating $\mathrm{C}$-section due to both a history of 2 prior C-sections and the potential for hemorrhage if the patient were to attempt vaginal delivery. We did not perform further diagnostic testing for varicosities of the esophagus or a Doppler ultrasound of the extremities. As is typical with vulvar varicosities, our patient had complete resolution of her vaginal varicosities by her 6-week postpartum exam.

\section{Discussion and Conclusions}

While vulvar varicosities are fairly common in pregnancy, vaginal varicosities are much less common. Much of the literature focuses on vulvar varicosities during pregnancy, usually with spontaneous resolution within six weeks of delivery [15]. Treatment of these varicosities is generally conservative and symptomatic using a pelvic supporter for vulvar compression, support hose, leg elevation, minimizing sitting and standing, and exercise [16]. Several of the reported cases of vaginal varicosities are associated with underlying venous congestion due to portal hypertension $[2,10,17]$. However, vaginal varicosities have rarely been reported, with only 10 reported cases between 1967 and 2016 which could be found in general reviews of the literature $[1,2,6,10,13$, $17,18]$. Vaginal varicosities are believed to be rare due to the number of outlets for venous flow via venous plexuses [10]. The uterus and vagina both have their respective venous plexuses that drain into the hypogastric veins [10]. Orlando et al. hypothesize that the loss of uterine venous plexus,

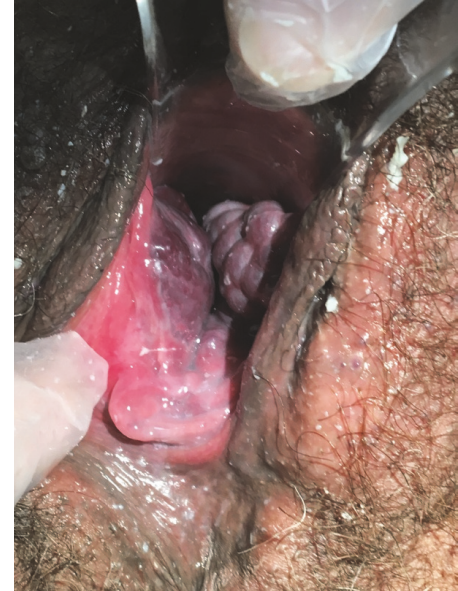

FIGURE 1: Vaginal varicosities protruding beyond hymenal ring.

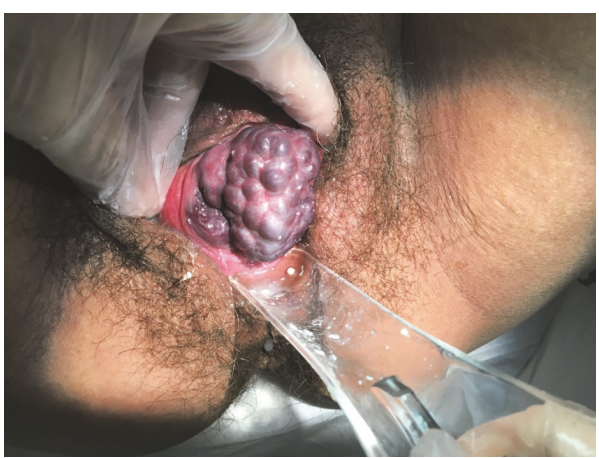

FIGURE 2: Vaginal Varicosities exposed during vaginal speculum exam.

such as in the case of a hysterectomy, creates a situation in which congestion of the vaginal network could occur creating an ideal environment for varicosities formation [2].

Pregnancy itself causes several physiologic changes that favor varicosities formation. A study by Gant et al. demonstrated that pregnancy normally leads to acquired vascular refractoriness to Angiotensin II (ATII) [19]. Prostacyclin (PGI2) which has been implicated in angiotensin resistance during normal pregnancy is increased during late pregnancy [20]. The femoral venous pressure rises gradually from approximately $8 \mathrm{mmHg}$ at the beginning of pregnancy to approximately $24 \mathrm{mmHg}$ at term [21]. However, antecubital venous pressure does not change [21]. These asymmetrical venous pressure changes are likely a product of IVC compression by the growing fetus. The venous blood of the pelvis drains mainly through three pathways: internal iliac vein, femoral vein, and ovarian vein. Incompetence of the femoral vein is the most common cause for vulvar varicosities in nonpregnant women [12]. However, in pregnant women decreased pelvic venous return and IVC occlusion due to the enlarging uterus contribute to the formation of vulvar and vaginal varicosities [22]. The combination of physiologic ATII resistance of the vasculature and increased pressure 
caused by a growing uterus could allow for significant venous congestion and varicosities formation.

Vaginal varicosities can also occur due to diseases of hepatic origin or from a rare condition known as KlippelTrenaunay syndrome, both of which can be further exacerbated during pregnancy. Klippel-Trenaunay syndrome is a rare disease, occurring in approximately 1 in 30000 live births. It is characterized by a triad of capillary malformations, vascular anomalies, and hypertrophy of bony and soft tissues. It can also present as varicosities in variable locations [23, 24]. Hepatic diseases that induce portal hypertension such as liver cirrhosis, NASH, and chronic hepatitis can contribute to varicosities formation [10]. However our patient did not exhibit any prior symptoms of this Klippel-Trenaunay syndrome nor did she have a history of hepatic disease, making these two conditions unlikely explanations for her varicosities.

Since vulvar varicosities are likely to resolve 6 weeks postpartum, it may be reasonable to assume that vaginal varicosities are also likely to resolve spontaneously; thus conservative management was taken before other interventions were made. Treatment options for vulvar varicosities include sclerotherapy or local excision for mild vulvar varicosities $[5,11,12]$. However, there is little information on the management of vaginal varicosities that do not self-resolve or are not due to a hepatic cause. Orlando et al. reviewed 6 cases of vaginal varicosities and their subsequent treatment. One of the cases had liver disease with resultant portal hypertension and three had known histories of total radical hysterectomy suggesting lack of uterine vascular network leading to increased venous pressure in the vaginal venous plexus. Four of the patients made complete recoveries by 34 months following a variety of treatments including partial vaginectomy, transvaginal ligation, and tamponade followed by balloon-occluded retrograde obliteration, tamponade, and surgical hemostasis followed by TIPS, and TIPS was followed by liver transplantation [2]. As for the other two cases, one died due to alcohol intoxication and the other from perioperative death [2].

The most likely and significant potential complications from our patient's vaginal varicosities include hemorrhage and thromboses during delivery. Several case reports have discussed bleeding from vaginal varicosities with etiologies rooted in portal hypertension $[10,18]$. Kikuchi et al. documented a case of massive vaginal bleeding in a patient with vaginal varicosities after delivery of a $2562 \mathrm{~g}$ male infant with resultant hypotension of $64 / 35 \mathrm{mmHg}$ treated with vaginal packing and blood transfusion [13]. Similarly, McHugh et al. reported a case of massive hemorrhage from vaginal varicosities in a nonpregnant 58-year-old patient suffering nonalcoholic steatohepatitis successfully treated with aggressive resuscitation and liver transplant [10]. In contrast to this, Furuta et al. noted that in spite of the concern over potential hemorrhage, the risk appears to be minor due to the shrinking and compression of vulvovaginal varicosities during the second stage of labor by the descending fetal head [4]. In spite of the potentially minimal risk of hemorrhage during vaginal delivery, it was decided that our patient's baby will be delivered via C-section. Her prior history of multiple C-sections and the presence of massive vaginal varicosities made the option for vaginal birth too risky. Vaginal varicosities can pose a risk to pregnant patients wanting to deliver vaginally due to the risk of hemorrhage, although by themselves vaginal varicosities are not significantly hazardous. Providers should consider this small risk in conjunction with other risk factors in their patients when deciding whether to attempt vaginal delivery.

\section{Abbreviations \\ C-section: Cesarean section \\ TIPS: Transjugular intrahepatic portosystemic shunt \\ ATII: Angiotensin II \\ PGI2: Prostaglandin I2 \\ IVC: Inferior vena cava \\ STI: $\quad$ Sexually transmitted infection \\ HPV: $\quad$ Human papilloma virus \\ NASH: Nonalcoholic fatty liver disease.}

\section{Conflicts of Interest}

The authors declare that they have no conflicts of interest.

\section{References}

[1] J. H. Kim and H. L. Lee, "A case of vaginal varix during pregnancy," Korean Journal of Obstetrics and Gynecology, vol. 55, no. 1, pp. 29-32, 2012.

[2] G. Orlando, P. Goffette, A. Geubel, and J. Lerut, "Vaginal bleeding complicating portal hypertension: A particular entity-Report of two cases and review of the literature," Transplant International, vol. 18, no. 12, pp. 1382-1385, 2005.

[3] T. Hurton, H. Morrill, M. Mascola, C. York, and B. Bromley, "Cervical varices: an unusual etiology for third-trimester bleeding," Journal of Clinical Ultrasound, vol. 26, no. 6, pp. 317-319, 1998.

[4] N. Furuta, E. Kondoh, S. Yamada et al., "Vaginal delivery in the presence of huge vulvar varicosities: a case report with MRI evaluation," European Journal of Obstetrics \& Gynecology and Reproductive Biology, vol. 167, no. 2, pp. 127-131, 2013.

[5] S. W. S. Leung, P. L. Leung, P. M. Yuen, and M. S. Rogers, "Isolated vulval varicosity in the non-pregnant state: a case report with review of the treatment options," Australian and New Zealand Journal of Obstetrics and Gynaecology, vol. 45, no. 3, pp. 254-256, 2005.

[6] S. Jindal, A. Dedhia, S. Tambe, and H. Jerajani, "Vulvovaginal varicosities: an uncommon sight in a dermatology clinic," Indian Journal of Dermatology, vol. 59, no. 2, p. 210, 2014.

[7] V. Choudhary and M. B. Bellad, "Varicosities of vulva during pregnancy- a rare case report," Journal of Dental and Medical Sciences, vol. 16, no. 1, pp. 75-76, 2017.

[8] R. Tanaka, Y. Fujita, K. Ishibashi Hiasa et al., "Successful Management of Pregnancy Complicated by Klippel-Trenaunay Syndrome Using MR Angiography-Based Evaluation," Case Reports in Obstetrics and Gynecology, vol. 2011, 4 pages, 2011.

[9] T. G. Gündoğan and Y. Jacquemyn, "Klippel-Trenaunay Syndrome and Pregnancy," Obstetrics and Gynecology International, vol. 2010, 3 pages, 2010. 
[10] P. P. McHugh, H. Jeon, R. Gedaly, T. D. Johnston, P. D. DePriest, and D. Ranjan, "Vaginal varices with massive hemorrhage in a patient with nonalcoholic steatohepatitis and portal hypertension: successful treatment with liver transplantation," Liver Transplantation, vol. 14, no. 10, pp. 1538-1540, 2008.

[11] A. H. Scultetus, J. L. Villavicencio, D. L. Gillespie, T. C. Kao, and N. M. Rich, "The pelvic venous syndromes: analysis of our experience with 57 patients," Journal of Vascular Surgery, vol. 36, no. 5, pp. 881-888, 2002.

[12] J. T. Hobbs, "Varicose veins arising from the pelvis due to ovarian vein incompetence," International Journal of Clinical Practice, vol. 59, no. 10, pp. 1195-1203, 2005.

[13] N. Kikuchi, S. Ohira, R. Asaka, A. Takatsu, H. Kobara, H. Ando et al., "A case of vaginal varices that caused massive bleeding after vaginal delivery," The Shinshu Medical Journal, vol. 64, no. 1, pp. 35-39, 2016 (Japanese).

[14] S. S. ADLER, "Extensive varix of vulva and vagina in full term pregnancy; delivery by cesarean section," American Journal of Obstetrics \& Gynecology, vol. 51, pp. 272-274, 1946.

[15] L. L. Veltman and D. R. Ostergard, "Thrombosis of vulvar varicosities during pregnancy," Obstetrics \& Gynecology, vol. 39, no. 1, pp. 55-56, 1972.

[16] D. Bell, P. B. Kane, S. Liang, C. Conway, and C. Tornos, "Vulvar varices: an uncommon entity in surgical pathology," International Journal of Gynecological Pathology, vol. 26, no. 1, pp. 99-101, 2007.

[17] L. S. Eriksson, C. Hårdstedt, D. Law, and L. Thulin, "Massive haemorrhage from vaginal varicose veins in patient with liver cirrhosis," The Lancet, vol. 319, no. 8282, p. 1180, 1982.

[18] M. J. Kreek, J. V. Raziano, R. E. Hardy, and G. H. Jeffries, "Portal hypertension with bleeding vaginal varices., Annals of Internal Medicine, vol. 66, no. 4, pp. 756-759, 1967.

[19] N. F. Gant, G. L. Daley, S. Chand, P. J. Whalley, and P. C. MacDonald, "A study of angiotensin II pressor response throughout primigravid pregnancy," The Journal of Clinical Investigation, vol. 52, no. 11, pp. 2682-2689, 1973.

[20] S. A. Friedman, "Preeclampsia, a review of the role of prostaglandins," Obstetrics and Gynecology, vol. 71, no. 1, pp. 122-137, 1988.

[21] F. Cunningham, K. J. Leveno, S. L. Bloom, C. Y. Spong, J. S. Dashe, and B. L. Hoffman, Williams Obstetrics, McGraw-Hill, New York city, NY, USA, Twenty-Fourth edition, 2013.

[22] C. E. McLennan, "Antecubital and femoral venous pressure in normal and toxemic pregnancy," American Journal of Obstetrics \& Gynecology, vol. 45, no. 4, pp. 568-591, 1943.

[23] A. R. Billington, J. Shah, J. B. Elston, and W. G. Payne, "Klippeltrenaunay syndrome," Eplasty, vol. 13, 2013.

[24] S. R. Watermeyer, N. Davies, and R. Goodwin, “The KlippelTrenaunay syndrome in pregnancy," BJOG: An International Journal of Obstetrics \& Gynaecology, vol. 109, no. 11, pp. 1301$1302,2002$. 


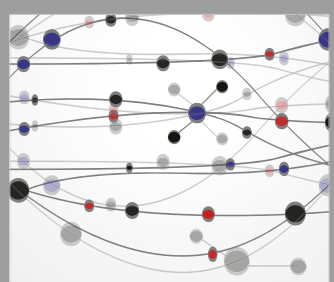

The Scientific World Journal
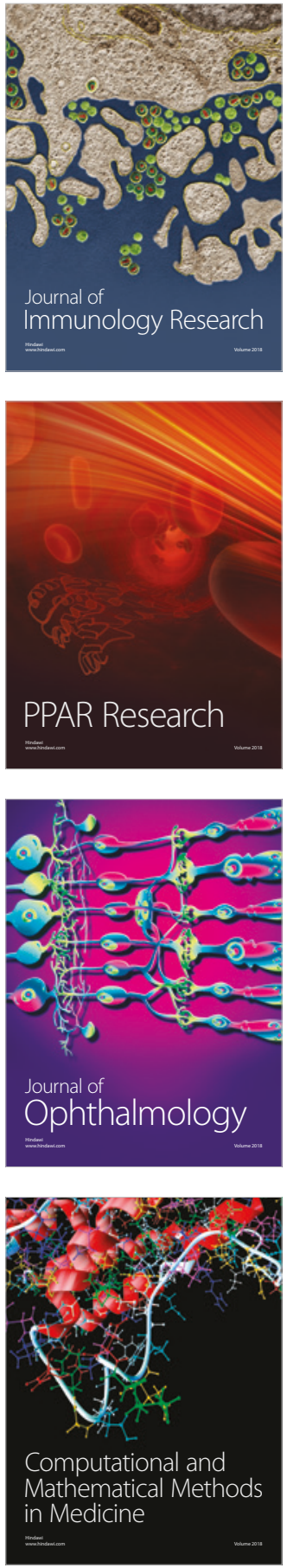

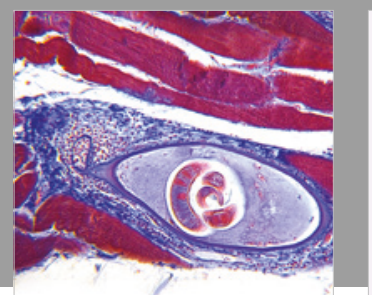

Gastroenterology Research and Practice

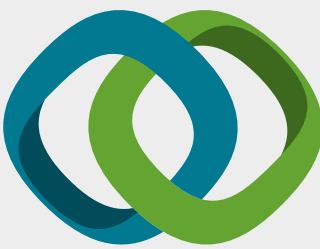

\section{Hindawi}

Submit your manuscripts at

www.hindawi.com
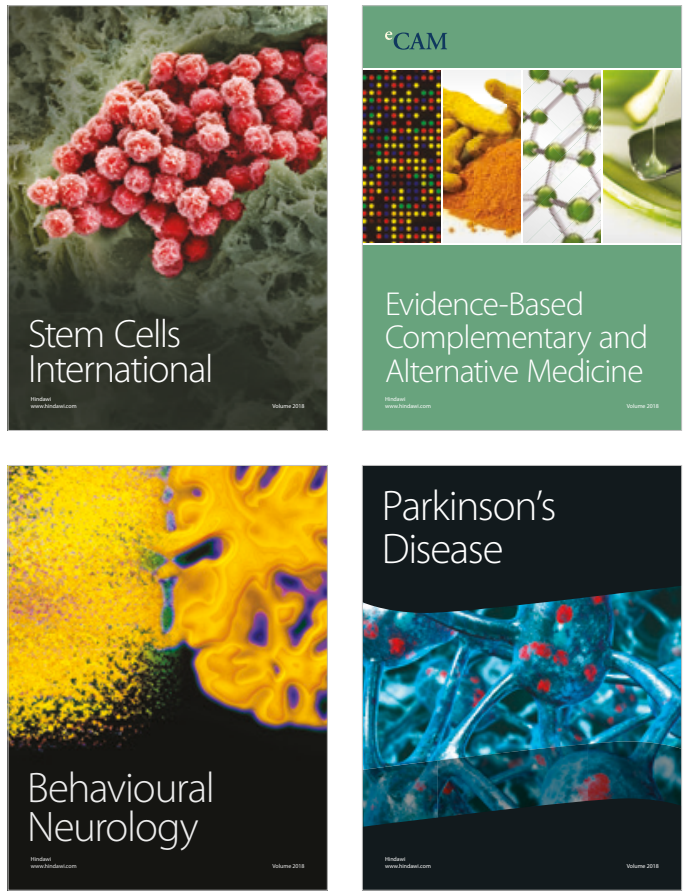

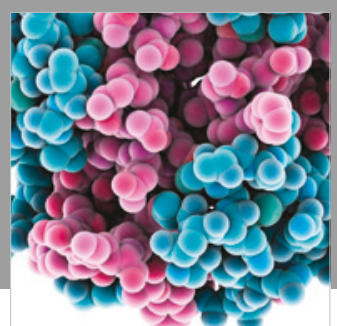

ournal of

Diabetes Research

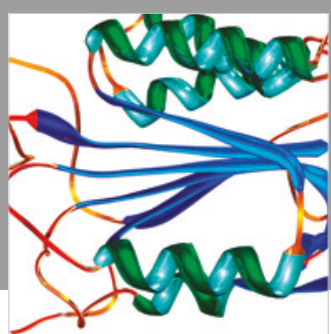

Disease Markers
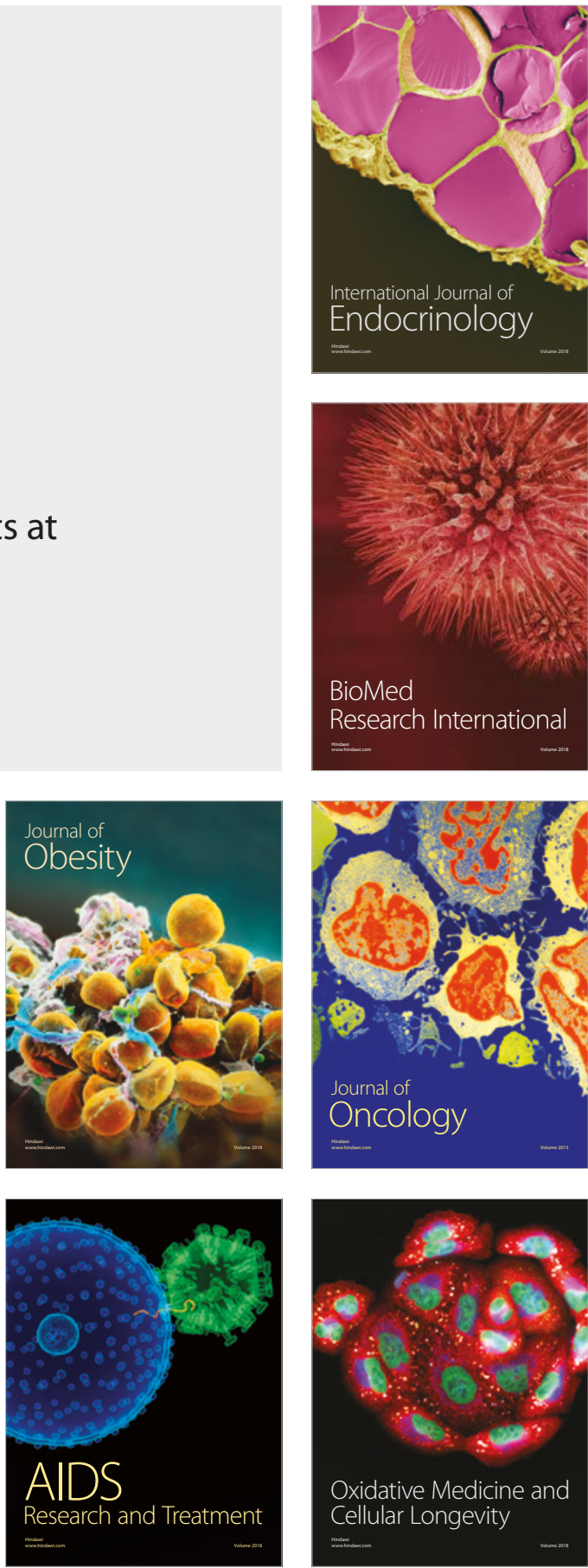